\title{
Analisis Penyebab dan Mekanisme Keruntuhan Lereng Sungai Konaweha, Studi Kasus Ruas Bts. Kab. Konawe Utara/Kab. Konawe - Pohara Km 29+750
}

\author{
Analysis of Causes and Mechanisms of Konaweha River Slope \\ Collapse, Case Study on Section Bts. Kab. Konawe Utara/Kab. \\ Konawe - Pohara Km 29+750
}

\author{
Sugiarto $^{1, a)}$, Mahendra Andiek Maulana ${ }^{2, b)}$ \& Yohanis Tulak Todingrara ${ }^{3, c)}$ \\ ${ }^{1)}$ Mahasiswa Magister Superspesialis Preservasi Jalan Pada Kondisi Geoteknik Tanah Sulit, ITS. \\ ${ }^{2)}$ Departemen Teknik Sipil, Fakultas Teknik Sipil, Perencanaan, dan Kebumian, ITS. \\ ${ }^{3)}$ Direktorat Jenderal Bina Marga, Kementerian PUPR.
}

Koresponden : ${ }^{a)}$ sugiarto1@pu.go.id, ${ }^{b}$ mahendrasipil@ gmail.com \&

c)yohanis.todingrara@pu.go.id

\begin{abstract}
ABSTRAK
Di Sulawesi Tenggara, ruas jalan Bts. Kab. Konawe Utara / Kab. Konawe - Pohara merupakan koridor utama yang pada tahun 2019 terjadi banjir yang mengakibatkan ruas jalan tergenang dan longsor pada beberapa titik sehingga perlu dilakukan penelitian terkait penyebab dan mekanisme terjadi longsoran di $\mathrm{Km} 29+750$. Penelitian dilakukan dengan merepresentasikan pengaruh perubahan tinggi muka air sungai dan tinggi muka air tanah serta pengaruh gerusan terhadap perubahan safety factor pada lereng dengan program bantu Plaxis. Dari hasil simulasi yang dilakukan, perilaku perubahan safety factor akibat pengaruh tinggi muka air sungai terjadi kenaikan nilai safety factor pada saat level muka air sungai naik. Namun akan terjadi penurunan nilai safety factor pada saat terjadi penurunan level muka air sungai secara tiba-tiba (drawdown). Pada kondisi lereng asli penurunan nilai safety factor sebesar $41 \%$, pada lereng dengan variasi gerusan 1 penurunan nilai safety factor sebesar $44 \%$, pada lereng dengan variasi gerusan 2 penurunan nilai safety factor sebesar $41 \%$, pada lereng dengan variasi gerusan 3 penurunan nilai safety factor sebesar 51\% sampai dengan nilai 0,93. Dari hasil analisa, lereng sungai konaweha mengalami keruntuhan terjadi pada saat penurunan level muka air sungai dengan kondisi tanah masih jenuh dan sudah terjadi gerusan 3 .
\end{abstract}

Kata Kunci : preservasi jalan, stabilitas lereng, plaxis, sungai Konaweha

\section{PENDAHULUAN}

Pemeliharaan jalan adalah kegiatan penanganan jalan, berupa pencegahan, perawatan dan perbaikan yang diperlukan untuk mempertahankan kondisi jalan agar tetap berfungsi secara optimal melayani lalu lintas sehingga umur rencana yang ditetapkan dapat tercapai. Pemeliharaan jalan meliputi sistem manajemen dengan didalamnya termasuk kegiatan penatausahaan dan pemanfaatan bagian-bagian jalan, leger jalan, serta preservasi aset jalan. Preservasi aset jalan sebagaimana dimaksud merupakan kegiatan pemeliharaan jalan yang dapat diikuti dengan rekonstruksi pada bagian-bagian jalan yang terencana antara lain akibat bencana alam (PerMen 13/11). Manajemen Aset Fasilitas adalah suatu ilmu pengetahuan dan tindakan dalam mengelola suatu fasilitas, agar fasilitas tersebut selalu berfungsi dengan baik, secara berkelanjutan, secara ekonomis, efisien, dan efektif dan dengan tetap berpegang pada prinsip sustainability (lingkungan, ekonomi dan sosial) (Suprayitno \& Soemitro, 2018). Ruas 
jalan No. 030 Bts. Kab. Konawe Utara/Kab. Konawe - Pohara dengan status jalan nasional merupakan jalan arteri primer yang menjadi koridor utama dari kota Kendari menuju kota Konawe Utara dan Kabupaten Morowali, Sulawesi Tengah. Keberadaan ruas jalan tersebut sangat penting untuk masyarakat Sulawesi Tenggara untuk distribusi logistik dari dan menuju kota Kendari dan akses kawasan industri pertambangan dimana secara geografis terletak dekat dan bersinggungan langsung dengan Sungai Konaweha terlihat pada Gambar 1. Sungai Konaweha merupakan salah satu sungai terpanjang serta terbesar di pulau Sulawesi dengan panjang sekitar 327,22 km (Misran, 2008). Pada tahun 2019 terjadi banjir pada sungai Konaweha yang mengakibatkan badan jalan terendam dan pada tahun 2020 badan jalan mengalami longsor seperti pada Gambar 2.

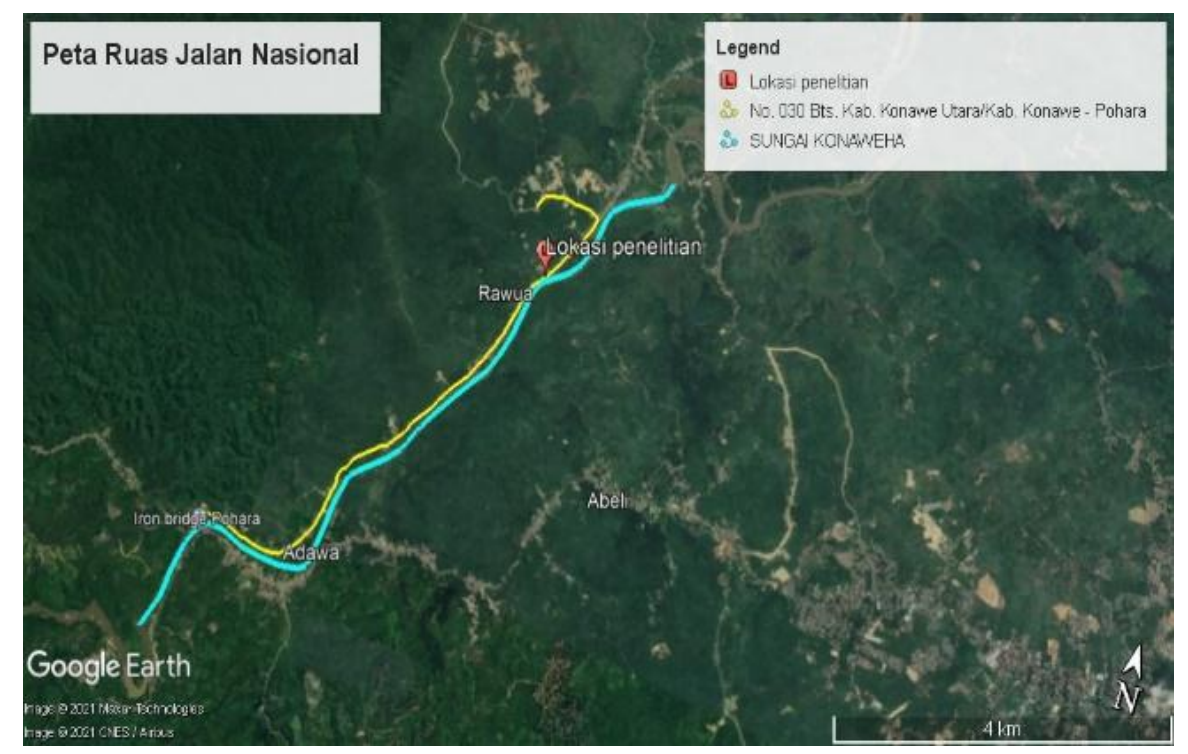

Gambar 1. Peta Lokasi Penelitian

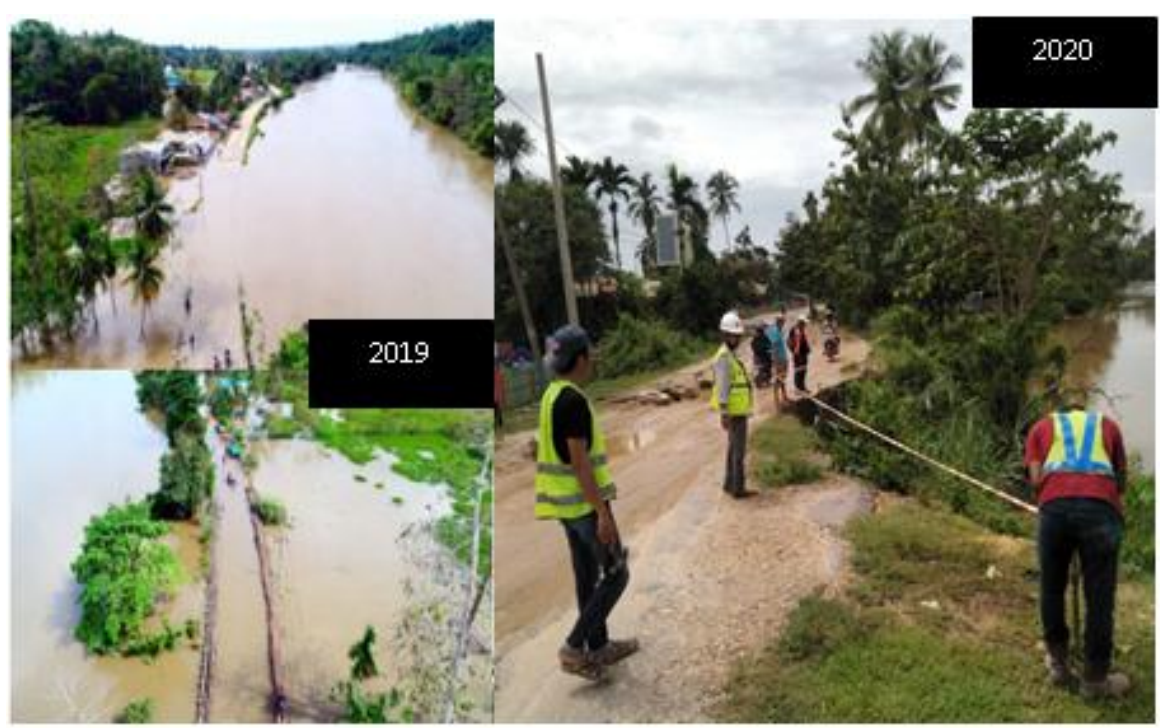

Gambar 2. Kronologis Terjadinya Longsor

Pada penelitian sebelumnya oleh Utami dan Caroline (2018) menyatakan semakin tinggi kadar air pada tanah, sudut geser dalam tanah $(\phi)$ nilainya semakin kecil. Perubahan kadar air tanah memberikan pengaruh pada nilai kohesi (c), semakin tinggi kadar air tanah maka nilai kohesi tanah semakin turun. Secara keseluruhan dapat dikatakan bahwa nilai tegangan geser tanah meningkat seiring dengan semakin rendahnya kadar air pada tanah, 
meskipun nilai sudut geser menurun dan kohesi meningkat. Menurut Kurniawan \& Hadimuljono (2021) Penyebab keruntuhan lereng dipengaruhi oleh beban, tegangan, geometri, dan kondisi air. Penurunan ketinggian air berdekatan dengan kemiringan. Air memberikan efek menstabilkan. Efek drawdown cepat terjadi dengan sangat cepat. Menurut Hardiyatmo (2006), jika permukaan tanah tidak horisontal komponen gravitasi akan menyebabkan tanah bergerak kebawah. Suryolelono (2002) mengemukakan bahwa peristiwa tanah longsor atau yang dikenal dengan gerakan massa tanah, batuan atau kombinasinya, sering terjadi pada lereng-lereng alam atau buatan, dan sebenarnya merupakan fenomena alam, yaitu alam mencari keseimbangan baru akibat gangguan atau faktor yang mempengaruhinya dan menyebabkan terjadinya pengurangan kuat geser serta peningkatan tegangan geser tanah. Slide, mudflows dan rockfalls adalah beberapa istilah yang digunakan untuk menggambarkan gerakan tanah/batuan dibawah pengaruh gravitasi (Bromhead, 2005)

Terkait dengan permsalahan tersebut perlu dilakukan analisa untuk mengetahui mekanisme dan penyebab terjadinya longsor. Analisa mekanisme dan penyebab longsor menggunakan metode back calculation analys dengan program bantu Plaxis dengan beberapa varisasi kondisi tinggi muka air dan gerusan. Hasil analisa ini dapat digunakan untuk mengetahui penyebab dan perilaku terjadinya longsor.

\section{METODE PENELITIAN}

Penelitian yang dilakukan menggunkan data primer dan sekunder. Data primer dari penelitian ini didapatklan dari pengujian lapangan berupa pengeboran dan pengambilan sampel tanah yang digunakan untuk pengujian laboratorium. Pengujian laboratorium yang dilakukan untuk menguji sifat fisik dan mekanik berupa pengujian kuat geser langsung dan kuat tekan bebas. Selain pengambilan sampel dan pengujian laboratorium, juga dilakukan pengukuran penampang melintang sungai. Sedangkan data sekunder dari penelitian ini berupa data borlog dari laporan terdahulu yang didapatkan dari Balai Pelaksanaan Jalan Nasional Sulawesi Tenggara seperti terlihat pada Gambar 3.

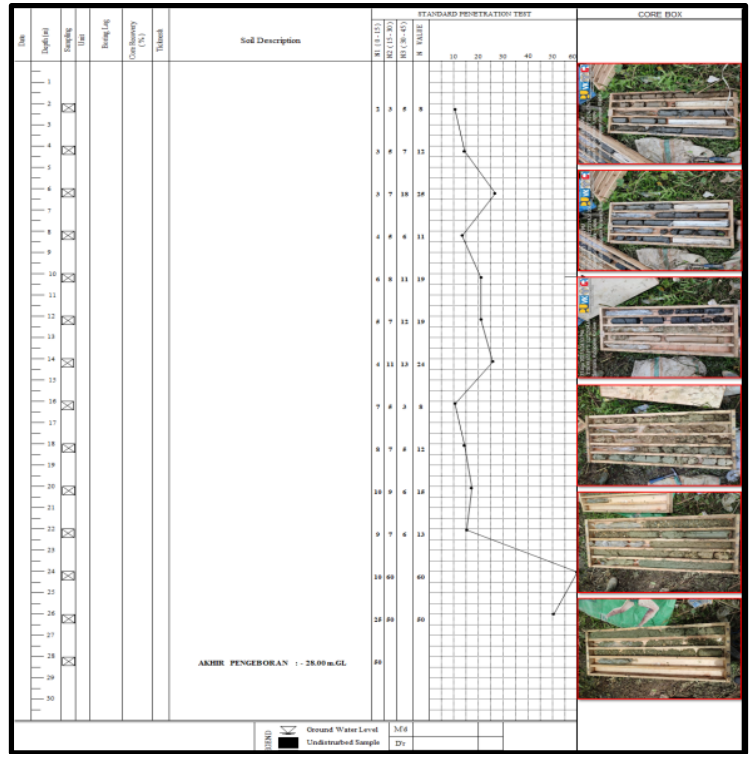

Gambar 3. Borlog Lokasi Longsoran

Analisa yang dilakukan dalam penelitian ini menggunakan metode back calculation analys dengan melakukan simulasi menggunakan program bantui Plaxis. Metoda analisis stabilitas lereng menggunakan teknik reduksi kekuatan geser metode elemen hingga, yaitu $\phi-c$ reduction procedure. Kelebihan metode ini menurut (Griffiths \& Lane, 1999) adalah asumsi dalam penentuan bidang longsor tidak dibutuhkan, bidang ini akan terbentuk secara alamiah 
pada zona dimana kekuatan geser tanah tidak mampu menahan tegangan geser yang terjadi. Selain itu metode ini mampu memantau perkembangan keruntuhan progresif termasuk overall shear failure.

Pada metode ini, parameter kuat geser tanah, yaitu $\tan \phi$ dan $\mathrm{c}$ dari tanah direduksi nilainya hingga mencapai keruntuhan. Simulasi yang dilakukan yaitu dengan mengasumsikan pada 2 (dua) kondisi yang mungkin terjadi pada saat longsor. Kondisi yang pertama adalah perilaku safety factor akibat perubahan tinggi muka air sungai, dimana diasumsikan pada saat terjadi banjir terjadi kenaikan level muka air sungai dari level muka air normal sampai dengan sejajar level elevasi jalan. Setelah itu kenaikan level muka air sungai diikuti kenaikan level muka air tanah sampai dengan level muka air sungai. Setelah level muka air sungai sama dengan level muka air tanah, terjadi penurunan level muka air sungai (drawdown) secara tibatiba seperti yang terlihat pada Gambar 4 Simulasi yang kedua adalah melihat perilaku akibat adanya gerusan pada lereng sungai Konaweha seperti terlihat pada Gambar 5.

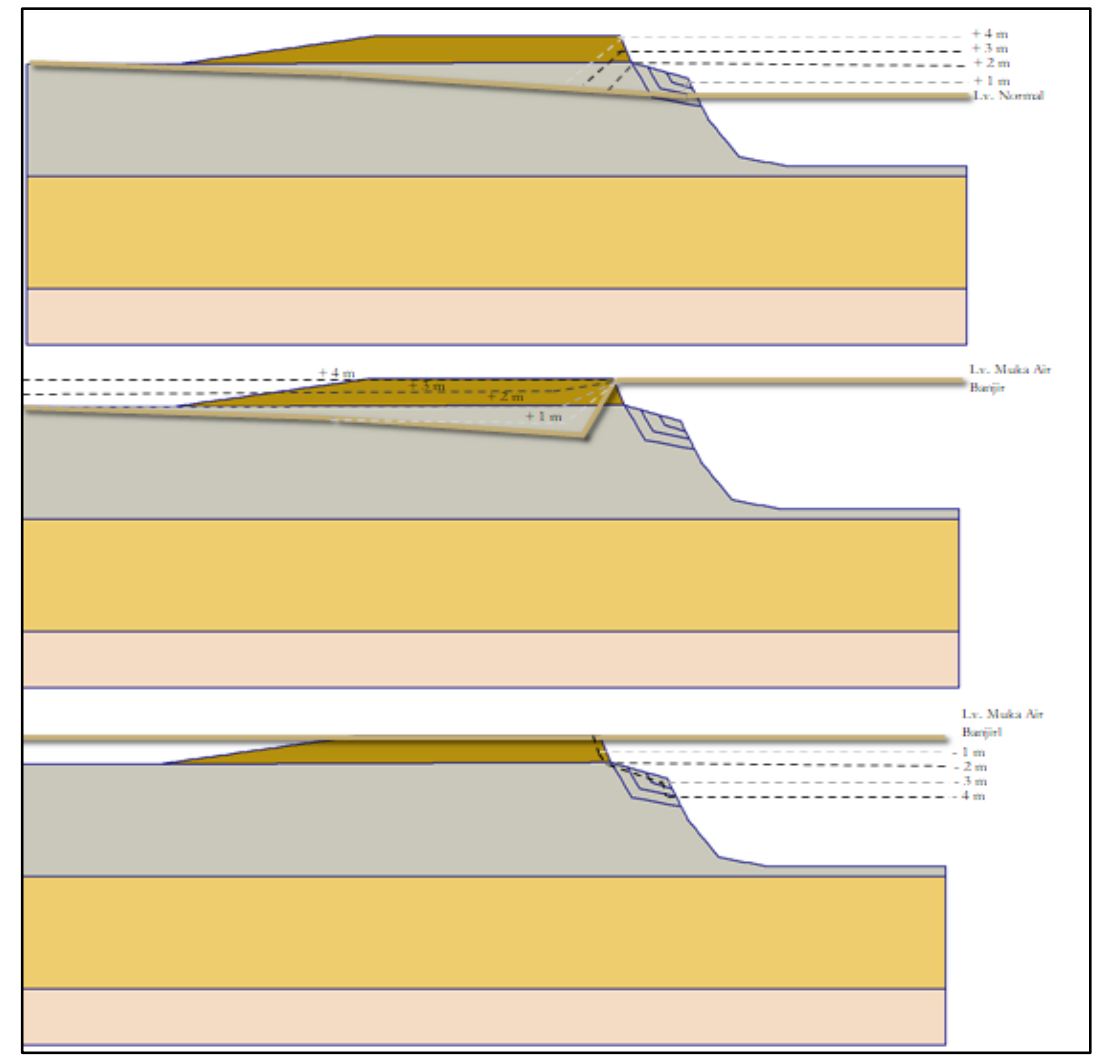

Gambar 4. Simulasi perubahan tinggi muka air sungai

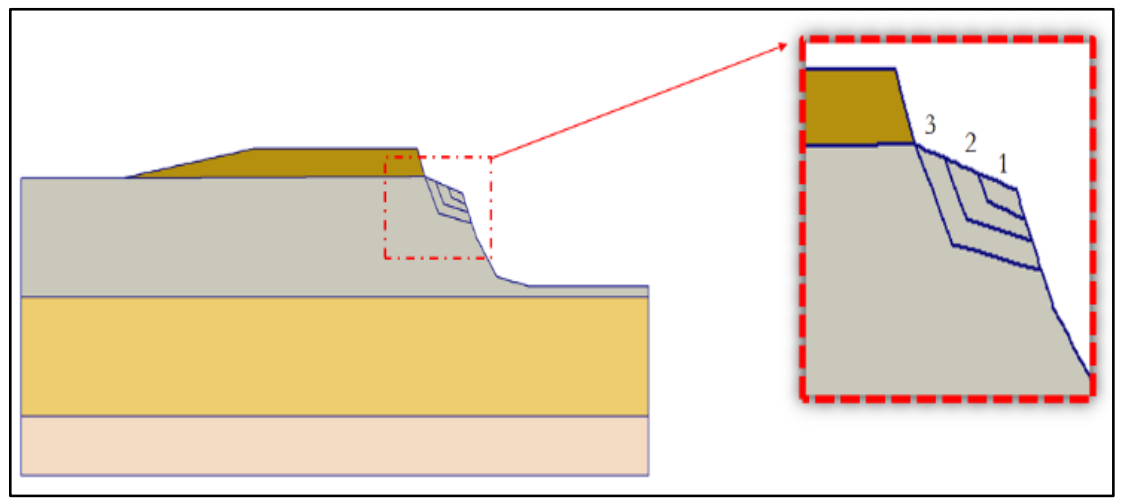

Gambar 5 Simulasi Gerusan 
Selain data properti tanah hasil pengujian laboratorium, beberapa data yang belum tersedia didapatkan dari tabel korelasi pada penelitian terdahulu.

Tabel 1. Hubungan antara Jenis Tanah dengan Nilai Sudut Geser Dalam

\begin{tabular}{lc}
\hline Jenis Tanah & Sudut Geser Dalam $(\boldsymbol{\phi})$ \\
\hline Kerikil Kepasiran & $35-40$ \\
Kerikil Kerakal & $35-40$ \\
Pasir Padat & $35-40$ \\
Pasir Lepas & 30 \\
Lempung Kelanauan & $25-30$ \\
Lempung & $20-25$ \\
\hline (Sumber: Das, 1993)
\end{tabular}

Tabel 2. Hubungan antara Jenis Tanah dengan Nilai Modulus Elastisitas Tanah

\begin{tabular}{ll}
\hline Jenis Tanah & $\mathbf{E}\left(\mathbf{k N} / \mathbf{m}^{\mathbf{2}}\right)$ \\
\hline Lempung & \\
Sangat Lunak & $300-300$ \\
Lunak & $2.000-4.000$ \\
Sedang & $4.500-9.000$ \\
Keras & $7.000-20.000$ \\
Berpasir & $30.000-42.500$ \\
Pasir & \\
Berlanau & $5.000-20.000$ \\
Tidak padat & $10.000-25.000$ \\
Padat & $50.000-100.000$ \\
Pasir dan Kerikil & \\
Padat & $80.000-200.000$ \\
Tidak padat & $50.000-140.000$ \\
Lanau & $2.000-20.000$ \\
Loess & $15.000-60.000$ \\
Serpih & $140.000-$ \\
\hline Sumber: Bowles, 1977 dalam Hardiyatmo, 1996) & 1.400 .000 \\
\hline
\end{tabular}

Tabel 3. Hubungan antara Jenis Tanah dengan Nilai Poisson Ratio

\begin{tabular}{lc}
\hline Jenis Tanah & $\boldsymbol{\mu}$ \\
\hline Lempung jenuh & $0,4-0,5$ \\
Lempung tak jenuh & $0,1-0,3$ \\
Lempung berpasir & $0,2-0,3$ \\
Lanau & $0,3-0,35$ \\
Pasir padat & $0,2-0,4$ \\
Pasir kasar (angka pori, e $=0,4-0,7)$ & 0,15 \\
Lempung halus (angka pori, e = 0,4-0,7) & 0,25 \\
Batu (agak tergantung dari macamnya) & $0,1-0,4$ \\
Loess & $0,1-0,3$ \\
\hline
\end{tabular}

(Sumber: Bowles, 1977 dalam Hardiyatmo, 1996) 
Tabel 4. Korelasi Nilai N-SPT dengan Berat Volume Tanah

\begin{tabular}{lccccc}
\hline $\mathbf{N}$ & $<\mathbf{4}$ & $\mathbf{4 - 6}$ & $\mathbf{6 - 1 5}$ & $\mathbf{1 6 - 2 5}$ & $>\mathbf{2 5}$ \\
Berat Volume $(\gamma), \mathrm{kN} / \mathrm{m}^{3}$ & $14-18$ & $16-18$ & $16-18$ & $16-20$ & $>20$ \\
$\mathrm{qu}, \mathrm{kPa}$ & $<25$ & $20-50$ & $30-60$ & $40-200$ & $>100$ \\
Kosistensi & Sangat Lunak & Lunak & Menengah & Kaku & Keras \\
\hline (Sumber: Lambe \& Whitman, 1969) & & & & &
\end{tabular}

Tabel 5. Parameter Tanah Input Plaxis

\begin{tabular}{|c|c|c|c|c|}
\hline Soil type & \multicolumn{2}{|l|}{ Description } & k. $\mathbf{m} / \mathbf{s}$ & Drainage \\
\hline $\begin{array}{l}\text { Cobbles and } \\
\text { boulders }\end{array}$ & \multicolumn{2}{|c|}{$\begin{array}{l}\text { Flow may be turbulent, Darcy's law may } \\
\text { not be valid }\end{array}$} & 1 & Very good \\
\hline \multirow[t]{3}{*}{ Gravels } & Coarse & Uniformly graded & 1,E-01 & \\
\hline & Clean & coarse aggregate & $1, \mathrm{E}-02$ & \\
\hline & & & $1, \mathrm{E}-03$ & \\
\hline $\begin{array}{l}\text { Greavel sand } \\
\text { mixtures }\end{array}$ & Clean & $\begin{array}{l}\text { Well graded } \\
\text { whitout fines }\end{array}$ & $1, \mathrm{E}-04$ & Good \\
\hline \multirow[t]{3}{*}{ Sand } & Clean, very fine & Fissured, & $1, \mathrm{E}-05$ & \\
\hline & Silty & desiccated, & 1,E-06 & \\
\hline & Stratified clay/silt & weathered clays & $1, \mathrm{E}-07$ & \\
\hline \multirow[t]{3}{*}{ Silt } & \multirow{5}{*}{$\begin{array}{l}\text { Homogeneous below } \\
\text { zone of weathering }\end{array}$} & $\begin{array}{l}\text { Compacted clays- } \\
\text { dry of optimum }\end{array}$ & $1, \mathrm{E}-08$ & \\
\hline & & & 1,E-09 & Poor \\
\hline & & & $1, \mathrm{E}-10$ & \\
\hline \multirow[t]{2}{*}{ Clays } & & Compacted clays- & $1, \mathrm{E}-11$ & Practically \\
\hline & & wet of optimum & $1, \mathrm{E}-12$ & impermeable \\
\hline Artificial & \multicolumn{4}{|c|}{$\begin{array}{l}\text { Bituminous. cements stabilized soil } \\
\text { Geosynthetic clay liner / Bentonite } \\
\text { enriched soil concrete }\end{array}$} \\
\hline
\end{tabular}

\section{ANALISIS PENELITIAN}

Setelah dilakukan analisa terhadap data tanah dan potongan melintang serta data borlog, didapatkan parameter tanah seperti yang terlihat pada Tabel 6 yang digunakan dalam input program Plaxis. 
Tabel 6. Parameter Tanah Input Plaxis

\begin{tabular}{|c|c|c|c|c|c|c|c|c|c|c|}
\hline \multirow[t]{2}{*}{$\begin{array}{c}\text { Kedala } \\
\text { man } \\
(\mathbf{m})\end{array}$} & \multirow[t]{2}{*}{$\begin{array}{l}\text { Jenis } \\
\text { Tanah }\end{array}$} & \multirow[t]{2}{*}{$\begin{array}{c}\text { N- } \\
\text { SPT }\end{array}$} & \multirow{2}{*}{$\begin{array}{c}\text { N- } \\
\text { SPT } \\
\text { (Rata- } \\
\text { Rata) }\end{array}$} & \multirow{2}{*}{$\begin{array}{c}\begin{array}{c}\text { Berat } \\
\text { isi } \\
\text { kering } \\
(\gamma \mathbf{d})\end{array} \\
\mathrm{kN} / \\
\mathrm{m}^{3}\end{array}$} & \multirow{2}{*}{$\begin{array}{c}\text { Berat } \\
\text { isi } \\
\text { jenuh } \\
(\gamma \mathbf{s a t})\end{array}$} & \multirow{2}{*}{$\begin{array}{c}\text { kx } \\
\text { m /hari }\end{array}$} & \multirow[t]{2}{*}{$\begin{array}{l}\text { Poiss } \\
\text { on } \\
(\mu)\end{array}$} & \multirow{2}{*}{$\begin{array}{c}\text { Modul } \\
\text { us } \\
\text { elastisit } \\
\text { as (E) }\end{array}$} & \multirow{2}{*}{$\begin{array}{c}\begin{array}{c}\text { Koh } \\
\text { esi } \\
\text { (c) }\end{array} \\
\mathrm{kN} / \\
\mathrm{m}^{2}\end{array}$} & \multirow{2}{*}{$\begin{array}{c}\text { Sudut } \\
\text { Geser } \\
\text { Dalam } \\
\text { (Phi) }\end{array}$} \\
\hline & & & & & & & & & & \\
\hline & Timbunan & & & 19 & 21 & 8,64 & 0,3 & 100000 & 10 & 40 \\
\hline $0-2$ & Lempung & 8 & 15 & 12,7 & 15,6 & $8,6 \mathrm{E}-06$ & 0,35 & 4500 & 32 & 1,27 \\
\hline $2-4$ & Kelanauan & 12 & & & & & & & & \\
\hline 4-6 & & 25 & & & & & & & & \\
\hline $6-8$ & & 11 & & & & & & & & \\
\hline $8-10$ & & 19 & & & & & & & & \\
\hline $10-12$ & Lempung & 19 & 15 & 16,0 & 18,0 & $8,6 \mathrm{E}-05$ & 0,3 & 30000 & 50,0 & 20,0 \\
\hline $12-14$ & & 24 & & & & & & & & \\
\hline $14-16$ & & 8 & & & & & & & & \\
\hline $16-18$ & & 12 & & & & & & & & \\
\hline $18-20$ & & 15 & & & & & & & & \\
\hline 20-22 & & 13 & & & & & & & & \\
\hline $22-24$ & Lempung & 60 & 50 & 18,0 & 20,0 & 8,6E-04 & 0,3 & 50000 & 200 & 30 \\
\hline $24-26$ & & 50 & & & & & & & & \\
\hline $26-28$ & & 50 & & & & & & & & \\
\hline
\end{tabular}

\section{Simulasi Perubahan Tinggi Muka Air Sungai}

Dari data potongan melintang sungai, data properti tanah dan juga data borlog, dilakukan simulasi terhadap perubahan tinggi muka air sungai dengan tiga tahapan yang sudah dijelaskan sebelumnya dengan hasil dapat dilihat pada Gambar 6 dan Tabel 7.

Pada fase pertama, dimana kondisi level muka air sungai naik terjadi kenaikan nilai safety factor sebesar $64 \%$ dari 1,32 menjadi 2,17. Pada fase kedua, dimana level muka air tanah naik mengikuti kenaikan level muka air sungai, maka terjadi penurunan safety factor dari 2,17 menjadi 1,89 atau sebesar 12\%. Pada fase ketiga dimana level muka air sungai turun secara tiba-tiba (drawdown) sampai dengan level muka air normal terjadi penurunan safety dari 1,89 menjadi 1,11 atau sebesar $41 \%$.

Dari hasil analisa dapat dilihat bahwa kondisi kritis lkereng terjadi pada saat kondisi level muka air sungai turun secara tiba-tiba (drawdown). Namu pada kondisi lereng asli penurunan tidak mengakibatkan keruntuhan dikarenakan safety factor masih lebih besar dari 1. 
Tabel 7. Perilaku Perubahan Safety factor Akibat Perubahan Tinggi Muka Air Sungai

\begin{tabular}{lll}
\hline Kondisi & Nilai SF & Level Muka Air Sungai \\
\cline { 3 - 3 } (meter) \\
\hline Muka Air Sungai Normal & 1,32 & -4 \\
Muka Air Sungai Naik & 1,49 & -3 \\
Muka Air Sungai Naik & 1,64 & -2 \\
Muka Air Sungai Naik & 1,83 & -1 \\
Muka Air Sungai Banjir, Tanah Belum Jenuh & 2,17 & 0 \\
Muka Air Tanah Naik & 2,17 & -4 \\
Muka Air Tanah Naik & 2,11 & -3 \\
Muka Air Tanah Naik & 2,05 & -2 \\
Muka Air Tanah Naik & 1,97 & -1 \\
Kondisi Banjir & 1,89 & 0 \\
Muka Air Sungai Turun & 1,63 & -1 \\
Muka Air Sungai Turun & 1,43 & -2 \\
Muka Air Sungai Turun & 1,23 & -3 \\
Muka Air Sungai Turun & 1,11 & -4 \\
\hline
\end{tabular}

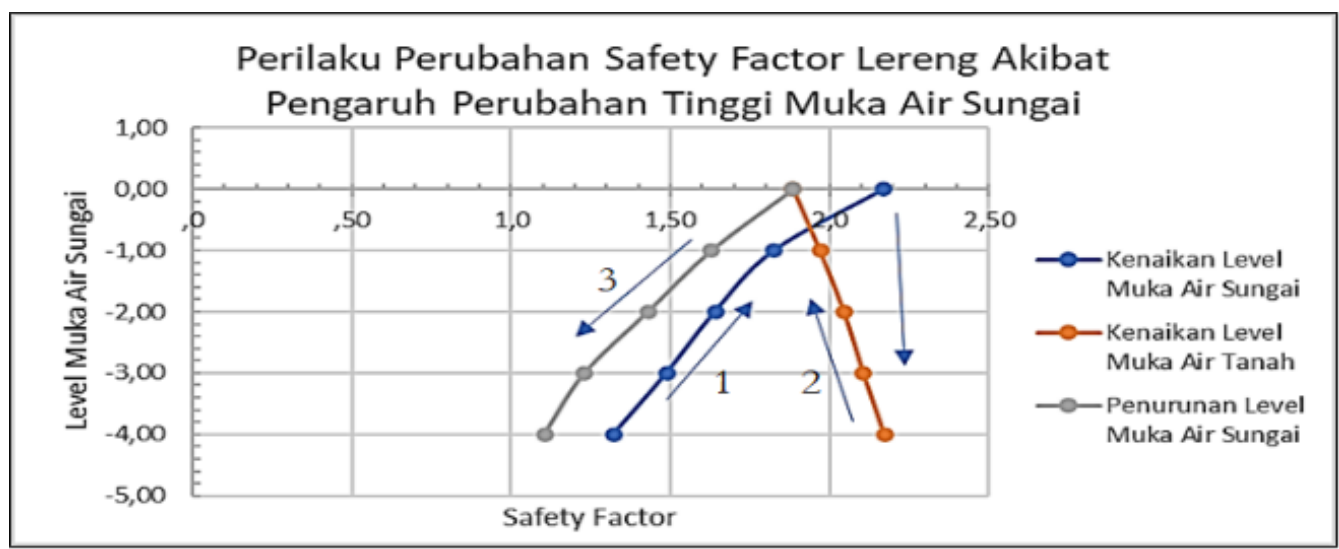

Gambar 6. Perilaku Perubahan Safety factor Akibat Perubahan Tinggi Muka Air Sungai

\section{Simulai Pengaruh Gerusan}

Setelah dilakukan simulasi perubahan safety factor akibat perubahan tinggi muka air sungai, diketahui kondisi kritis adalah pada saat drawdown. Namun pada lereng tersebut belum terjadi keruntuhan sehingga perlu dilakukan simulasi dengan menambahankan variasi gerusan pada yang mungkin terjadi dengan melihat kelongsoran yang terjadi dilapangan.

\section{Lereng Asli}

Pada kondisi lereng asli, akibat adanya fenomena drawdown, terjadi penurunan safety factor dari 1,89 menjadi 1,11 atau sebesar $41 \%$ seperti pada Gambar 7 Pada lereng asli belum terjadi keruntuhan dengan nilai safety factor pada kondisi kritis sebesar 1,1. 

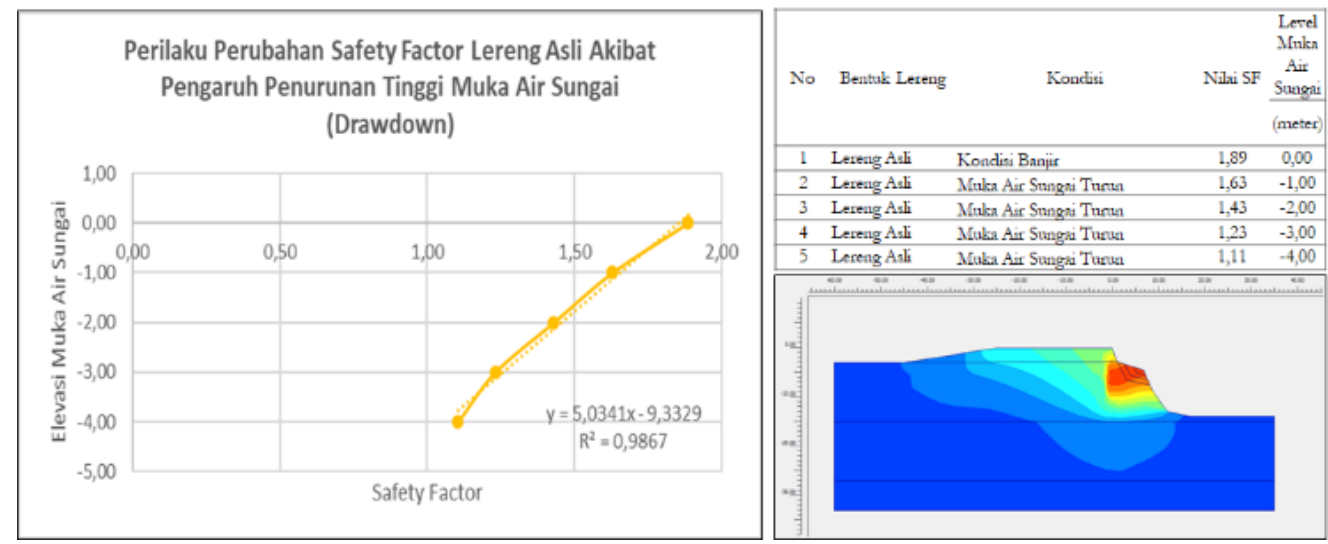

Gambar 7. Perilaku Perubahan Safety factor Pada Lereng Asli

\section{Lereng Dengan Gerusan 1}

Pada kondisi lereng dengan variasi gerusan 1 akibat adanya fenomena drawdown, terjadi penurunan safety factor dari 1,90 menjadi 1,06 atau sebesar 44\% seperti pada Gambar 8 Pada lereng dengan variasi gerusan 1 belum terjadi keruntuhan dengan nilai safety factor pada kondisi kritis sebesar 1,06.
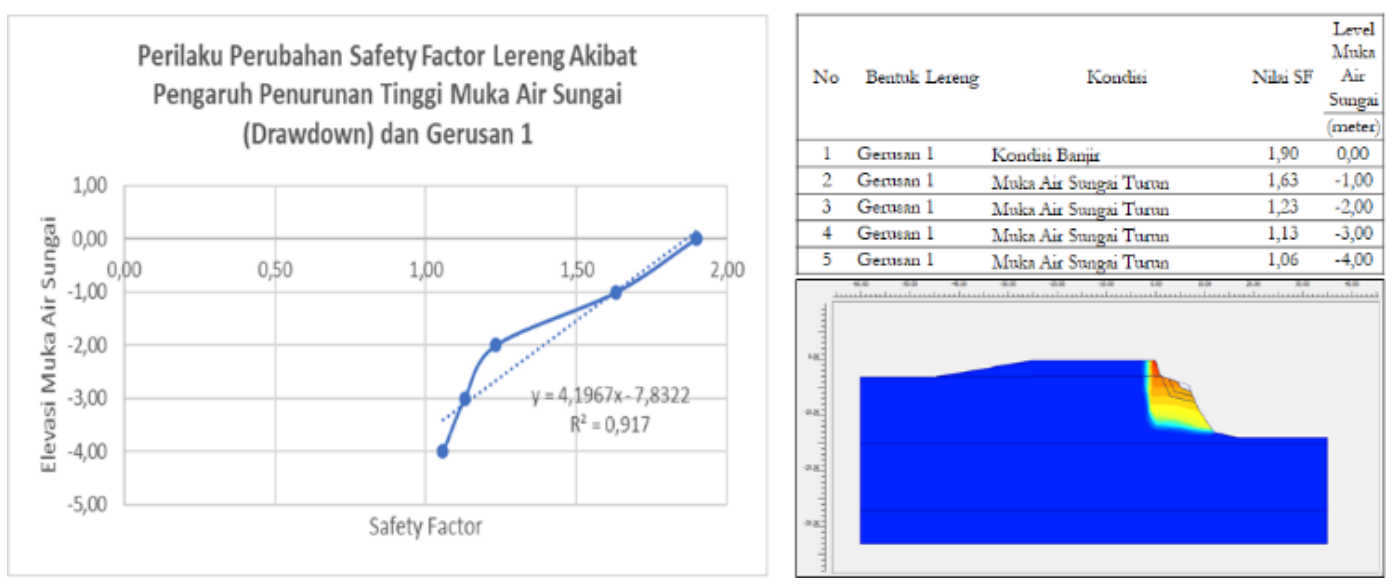

Gambar 8. Perilaku Perubahan Safety factor Pada Lereng Variasi Gerusan 1

\section{Lereng Dengan Gerusan 2}

Pada kondisi lereng dengan variasi gerusan 2 akibat adanya fenomena drawdown, terjadi penurunan safety factor dari 1,91 menjadi 1,12 atau sebesar $41 \%$ seperti pada Gambar 9 Pada lereng dengan variasi gerusan 2 belum terjadi keruntuhan dengan nilai safety factor pada kondisi kritis sebesar 1,12.
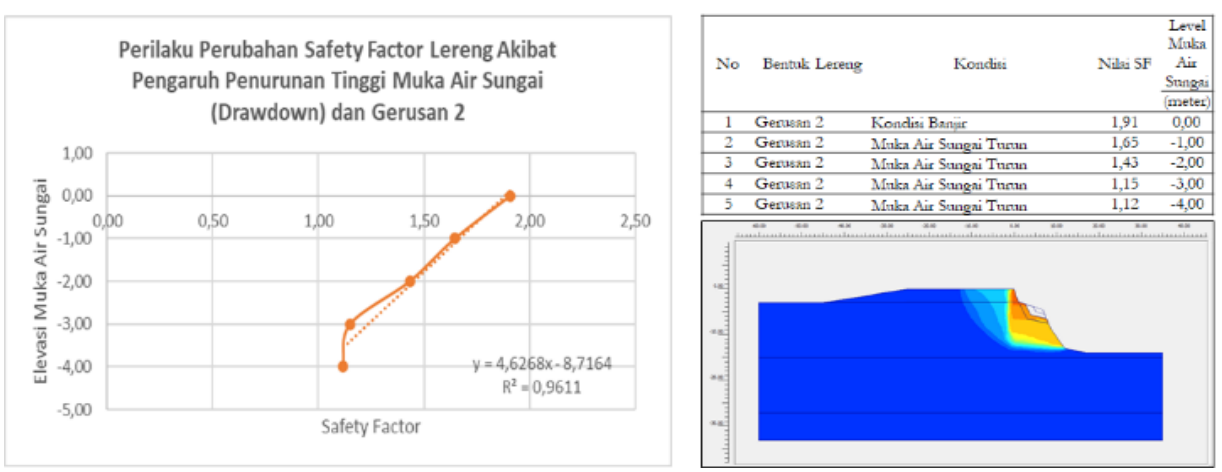

Gambar 9. Perilaku Perubahan Facety Factor Pada Lereng Variasi Gerusan 2 


\section{Lereng Dengan Gerusan 3}

Pada kondisi lereng dengan variasi gerusan 2 akibat adanya fenomena drawdown, terjadi penurunan safety factor dari 1,93 menjadi 0,93 atau sebesar $51 \%$ seperti pada Gambar 10 Pada lereng dengan variasi gerusan 3 terjadi keruntuhan dengan nilai safety factor pada kondisi kritis sebesar 0,93.

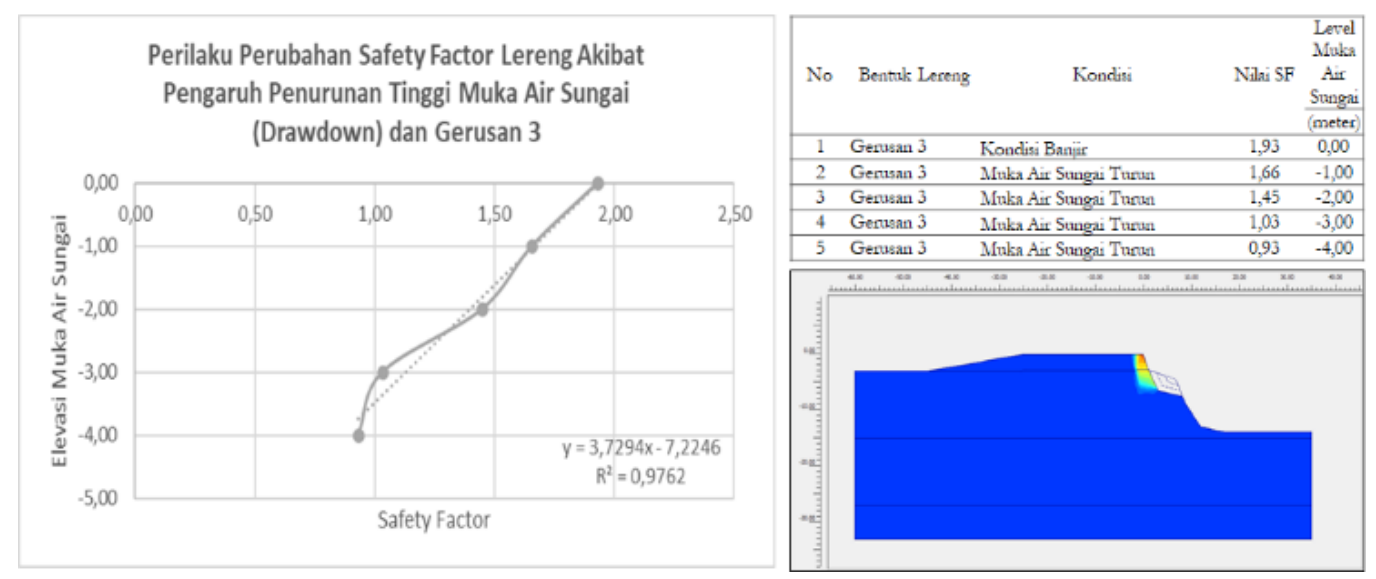

Gambar 10. Perilaku Perubahan Facety Factor Pada Lereng Variasi Gerusan 5

Dari hasil simulasi pemodelan dengan variasi gerusan, pada kondisi dengan variasi gerusan 3 terjadi keruntuhan pada saat terjadi penurunan level muka air sungai sampai dengan 4 meter.

\section{KESIMPULAN}

Dari hasil penelitian, setelah dilakukan analisa terhadap data, maka dapat beberapa kesimpulan yaitu:

- Pada lereng asli dengan kondisi level muka air sungai naik dari level muka air normal sampai dengan level jalan, terjadi kenaikan nilai safety factor sebesar 64\%. Hal itu disebabkan tekanan air sungai menjadi tekanan pasif yang melawan tekanan aktif tanah sehingga memberikan efek menstabilkan lereng.

- Pada lereng asli dengan kondisi level muka air tanah naik mengikuti kenaikan level muka sungai, terjadi penurunan nilai safety factor sebesar $12 \%$. Penurunan nilai stabilitas lereng terjadi akibat pengaruh kenaikan tekanan air pori yang disebabkan kenaikan level muka air tanah.

- Pada lereng asli dengan kondisi level muka air sungai turun (drawdown) sampai dengan level muka air normal dan kondisi tanah jenuh, terjadi penurunan nilai safety factor dari 1,89 menjadi 1,11 atau sebesar $41 \%$. Hal itu disebabkan tanah lereng masih dalam kondisi jenuh, sedangakn tekanan air sungai sebagai penahan hilang.

- Pada lereng variasi gerusan 1 dengan kondisi level muka air sungai turun (drawdown) sampai dengan level muka air normal dan kondisi tanah jenuh, terjadi penurunan nilai safety factor dari 1,90 menjadi 1,06 atau sebesar $44 \%$.

- Pada lereng variasi gerusan 2 dengan kondisi level muka air sungai turun (drawdown) sampai dengan level muka air normal dan kondisi tanah jenuh, terjadi penurunan nilai safety factor dari 1,91 menjadi 1,12 atau sebesar $41 \%$.

- Pada lereng variasi gerusan 3 dengan kondisi level muka air sungai turun (drawdown) sampai dengan level muka air normal dan kondisi tanah jenuh, terjadi penurunan nilai safety factor dari 1,93 menjadi 0,93 atau sebesar $51 \%$.

- Dari hasil analisa terhadap kondisi perubahan tinggi level muka air tanah dan sungai serta variasi gerusan, lereng sungai konaweha mengalami keruntuhan terjadi pada saat 
penurunan level muka air sungai dengan kondisi tanah masih jenuh dan sudah terjadi gerusan 3 .

\section{DAFTAR PUSTAKA}

Bowles, J. E. (1977). Foundation Analysis and Design.McGraw-Hill Kogakusha. Tokyo

Bromhead, E. N. (2005). The Stability of Slope. Taylor \& Francis. New York.

Das, B. M. (1988). Mekanika Tanah (Prinsip-prinsip Rekayasa Geoteknik) Jilid 1. (I. B. Mochtar, \& N. E. Mochtar, Trans.).Erlangga. Jakarta

Das, B. M. (1993). Mekanika Tanah Jilid 2. (I. B. Mochtar, \& N. E. Mochtar, Trans.).Erlangga. Surabaya

Griffiths, D. V., \& Lane, P. A. (1999). Slope stability analysis by finite elements. GeÂotechnique 49.

Hardiyatmo, H. C. (1996). Teknik Fondasi 1.Gramedia.Yogyakarta

Hardiyatmo, H. C. (2006). Penanganan Tanah Longsor \& Erosi.Gadjah Mada University Press. Yogyakarta.

Kurniawan, P., \& Hadimuljono, M. B. (2021). Applied Geotechnics for Engineers 2. Penerbit ANDI. Yogyakarta.

Lambe, T. W., \& Whitman, R. V. (1969). Soil Mechanics.John Wiley \& Son. New York.

Look, B. G. (2007). Handbook of Geotechnical Investigation and Design Tables. Taylor \& Francis. London.

Misran, F. (2008). Jaga DAS Untuk Ketahanan Pangan Sultra. Retrieved Februari 2, 2021, from https://m3sultra.wordpress.com/2008/05/13/lembar-informasi-2008-05-jaga-dasuntuk-ketahanan-pangan-sultra/

PerMen 13/11. Peraturan Menteri Pekerjaan Umum Nomor : 13/PRT/M/2011 tentang Pedoman Tata Cara Pemeliharaan dan Penilikan Jalan.

Suprayitno, H., \& Soemitro, R. A. (2018). Preliminary Reflexion on Basic Principle of Infrastructure Asset Management. Jurnal Manajemen Aset \& Fasilitas, $2,1$.

Suryolelono, K. B. (2002). Geosintetik Geoteknik. Nafiri. Yogyakarta.

Utami, G. S., \& Caroline, J. (2018). Analisis Pengaruh Perubahan Kadar Air Terhadap Parameter Kuat Geser tanah. Surabaya: Seminar Nasional Sains dan Teknologi Terapan VI. 